J. Clin. Chem. Clin. Biochem.

Vol. 25, 1987, pp. $61-70$

(C) 1987 Walter de Gruyter \& Co.

Berlin - New York

\title{
High Resolution Two-Dimensional Polyacrylamide Gel Electrophoresis of Cerebrospinal Fluid in Patients with Neurological Diseases
}

\author{
By A.T. Endler
}

Department of Laboratory Medicine, Mayo Clinic, Rochester, MN, USA and

Institut für Klinische Chemie und Laboratoriumsmedizin, Vienna, Austria and

Department of Pathology and Laboratory Medicine, University of Pennsylvania, Philadelphia, PA, USA

D. S. Young

Department of Laboratory Medicine, Mayo Clinic, Rochester, MN, USA and

Department of Pathology and Laboratory Medicine, University of Pennsylvania, Philadelphia, PA, USA

\section{Takehiko Yanagihara}

Department of Neurology, Mayo Clinic, Rochester, MN, USA

Rose M. Currie

Department of Laboratory Medicine, Mayo Clinic, Rochester, MN, USA

and

J. Reid

Department of Pathology and Laboratory Medicine, University of Pennsylvania, Philadelphia, PA, USA

(Received April 28/September 29, 1986)

Summary: The protein pattern of cerebrospinal fluid (CSF) of 334 patients with various neurological and systemic diseases was investigated by high resolution two-dimensional electrophoresis (2-DE). 2-DE gels of normal CSF conntain proteins which are not detectable in 2-DE gels of serum. Disturbances of the bloodbrain or blood=CSF barrier, and degenerative diseases of the brain and malignant diseases produce specific changes on 2-DE gels of the CSF. The appearance of 10 spot areas in the light chain region of 2-DE gels seem to be connected with the diagnosis of multiple sclerosis. The sensitivity and the specificity of these spot areas for the diagnosis of multiple sclerosis are described. Proteins within the ten spot areas are immunoglobulin light chains or substances which cross-react very strongly with light chain antibodies as demonstrated by immunoblotting and immunoabsorption.

\section{Introduction}

Cerebrospinal fluid (CSF) is in close contact with the brain, and some proteins in CSF are derived from the central nervous system (CNS) (1). Many serum proteins are present in CSF of healthy individuals, but at a concentration one two-hundredth of that in serum. Two-dimensional electrophoresis (2-DE) of serum and CSF proteins has demonstrated that certain proteins are normally present in only one of the two fluids (2-9). Diseases involving the CNS may 
markedly affect the protein pattern of the CSF. Such changes, c.g. multiple sclerosis (1) or disorders of the blood-brain barrier (10) are used diagnostically. Malignant and infectious diseases may also alter CSF protein concentrations and patterns.

High resolution 2-DE in polyacrylamide gels (PAGE), as described originally by $O^{\prime}$ Farrell (11) and later adapted for serum by Anderson \& Anderson (12), is a very powerfull technique for resolving proteins in biological fluids, particularly when it is combined with a silver staining procedure (13). This method has been adapted for CSF by Merril et al. (14) and we have used a modification of the Anderson procedure (1).

\section{Materials and Methods}

\section{Patients and cerebrospinal fluid}

Three hundred and thirty four CSF specimens were collected from patients from 3 to 87 years of age who underwent diagnostic spinal taps and spinal myelograms at the Mayo Clinic. Approximately equal numbers of the sexes were represented. CSF specimens were received in the laboratory within one hour after spinal tap. Specimens were centrifuged to remove cellular elements and stored at $-70^{\circ} \mathrm{C}$ until analysed by 2-DE.

Clinical analysis and the laboratory procedure were carried out independently.

Sixteen patients who had no evidence of any organic neurological or systemic diseases such as vascular or tension headache, idiopathic scoliosis, tension myalgia, or atypical facial pain, were used as the control group. Other patients were divided into 13 disease groups (tab. 1).

\section{Specimen preparation}

Specimens containing $300 \mu \mathrm{g}$ of protein (determined turbidimetrically on the aca III (Du Pont, Inc., Wilmington, DE, USA) were dialysed against $0.1 \mathrm{~mol} / \mathrm{l}$ ammonium formate and concentrated by lyophilization. In preliminary experiments we found that with this procedure at least $96 \%$ of the starting protein quantity was recovered. Protein was dissociated by heating for $5 \mathrm{~min}$ at $95^{\circ} \mathrm{C}$ in $100 \mu \mathrm{l}$ sample preparation buffer, $\mathrm{pH} 9.5$, containing $20 \mathrm{~g} / \mathrm{l}$ sodium dodecylsulphate (SDS), $50 \mathrm{~g} / \mathrm{l}$ mercaptoethanol, $50 \mathrm{mmol} / 1$ cyclohexylamino sulphonic acid (CHES, Calbiochem, San Diego, CA, USA), and $100 \mathrm{~g} / \mathrm{l}$ glycerol. Ten $\mu l$ samples of this preparation were loaded in duplicate on ISOgels.

\section{Electrophoresis}

2-DE was performed by a modification of the ISO-DALT system of Anderson \& Anderson (12) as described previously $(2,15)$. The first or ISO-dimension is isoelectric focusing in polyacrylamide $(35 \mathrm{~g} / \mathrm{l})$ under denaturing conditions: $9 \mathrm{~mol}$

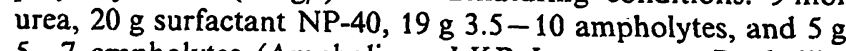
5-7 ampholytes (Ampholines, LKB Instruments, Rockville, $\mathrm{MD}, \mathrm{USA}$ ), $1.6 \mathrm{~g}$ arginine and $1.0 \mathrm{~g}$ lysine were added to 11 of acrylamide solution. Isoelectric focusing was performed.at $10600 \mathrm{Vh}$ after prefocusing for $1 \mathrm{~h}$ at $200 \mathrm{~V}$ with $0.85 \mathrm{~g} / 1$ phosphoric acid as anolyte and $1.0 \mathrm{~mol} / \mathrm{l}$ sodium hydroxide as catholyte. ISO-gels were equilibrated subsequently in a buffer containing $20 \mathrm{~g} / \mathrm{l} \mathrm{SDS}$ for $8 \mathrm{~min}$ and quickly frozen in a solid
$\mathrm{CO}_{2} /$ ethanol bath.
Tabl. 1. Clinical diagnosis of patients.

\begin{tabular}{|c|c|}
\hline Control & \\
\hline Demyelinating disease & \\
\hline Definitive multiple sclerosis & 14 \\
\hline Probable multiple sclerosis & 14 \\
\hline Possible multiple sclerosis & 21 \\
\hline Others & 9 \\
\hline Peripheral neuropathies & \\
\hline Polyradiculopathies & \\
\hline Disc syndromes, spinal stenosis etc. & \\
\hline Myelopathies & \\
\hline CNS degenerative diseases, including dementia & \\
\hline Encephalopathies & \\
\hline Seizures & \\
\hline Meningoencephalitis & . \\
\hline Hydrocephalus & \\
\hline CNS neoplasms & \\
\hline $\begin{array}{l}\text { Systemic malignancies without CNS } \\
\text { involvement }\end{array}$ & \\
\hline $\begin{array}{l}\text { Miscellaneous including syphilis and } \\
\text { post operative }\end{array}$ & \\
\hline
\end{tabular}

Total 334

The second dimension, SDS-PAGE in a $100 \mathrm{~g} / 1$ to $230 \mathrm{~g} / \mathrm{l}$ acrylamide gradient slab gel, was performed in DALT tanks (Electro/Nucleonics, Inc., Oak Ridge, TN, USA) with a buffer containing $3.5 \mathrm{mmol} / \mathrm{l} \mathrm{SDS}, 24 \mathrm{mmol} / \mathrm{l}$ tris, $0.2 \mathrm{~mol} / 1$ glycine.

2-DE gels were stained with ammoniacal silver nitrate and formaldehyde citrate $(15,16)$. Stained $2-\mathrm{DE}$ gels were photographed and inspected and evaluated visually. Spots on the 2DE gels of CSF were identified by comparison with a reference map of normal human serum (15). The reproducibility of 2DE has been described previously (15).

\section{Immunoabsorption}

Antibodies against the human kappa and lambda light chains (Dakopatts, Accurate Chemical \& Scientific Corporation, Westbury, NY, USA) were coupled to CNBr-activated Sepharose 4B (Pharmacia, Piscataway, NJ, USA) following the procedure described by the manufacturer and Dermer et al. (4). Antibody protein $\left(2 \mathrm{mg}\right.$ ) was coupled to $1 \mathrm{ml}$ gel at $4^{\circ} \mathrm{C}$ and incubated overnight in a buffer at pH 8.3 containing $0.1 \mathrm{~mol} / 1$ sodium bicarbonate and $0.5 \mathrm{~mol} / \mathrm{l}$ sodium chloride. Free ligands were blocked with $1 \mathrm{~mol} / \mathrm{l}$ ethanolamine at $\mathrm{pH} 8.0$ and excess protein was washed off with $0.1 \mathrm{~mol} / \mathrm{l}$ acetate buffer containing $0.5 \mathrm{~mol} / \mathrm{l}$ sodium chloride and $2 \mathrm{~g} / 1$ detergent Tween 20 . Antibody-coupled Sepharose was equilibrated and stored in phosphate-buffered saline pH 7.2 with $10 \mathrm{mg} / 1$ sodium azide.

Immunoabsorption was performed in microcolumns $(3 \mathrm{ml} \mathrm{dis}-$ posable syringes) filled with $1 \mathrm{ml}$ Sepharose coupled to the individual antibody. Three CSF and three human serum specimens, each containing $350 \mu \mathrm{g}$ protein were first absorbed on the anti-kappa antibody column, and in a second step the eluent was absorbed on the anti-lambda antibody column. The specimen, from which light chains had been depleted, was treated in the same way as the original CSF specimen (following dialysis and lyophilization) and subjected to 2-DE. Bound light chains were eluted in two steps; first with an acid glycine buffer $(0.1 \mathrm{~mol} / \mathrm{l}$ glycine and $0.5 \mathrm{~mol} / \mathrm{l}$ sodium chloride adjusted to pH 2.5 with $0.2 \mathrm{~mol} / 1$ hydrochloric acid), then elution was repeated with $100 \mathrm{ml} / 1$ dioxane in the same buffer. The $\mathrm{pH}$ of the eluate was immediately raised by addition of solid tris. The eluate was treated in the same way as the ábsorbed samples. 


\section{Blotting and immuno staining}

Protein was transfered from the SDS-Polyacrylamide gel onto a nitrocellulose sheet (Schleicher \& Schuell, Inc., Keene, NH, USA) in a Trans Blot Cell (Bio-Rad Laboratories, Richmond, CA, USA) according to Symington (17). The transfer buffer consisted of $25 \mathrm{mmol} / 1$ tris, $192 \mathrm{mmol} / 1$ glycine and $200 \mathrm{ml} / 1$ methanol at $\mathrm{pH} 8.3$. The blotting was performed at $150 \mathrm{~V}$ for $3 \mathrm{~h}$ with cooling; nitrocellulose sheets were removed from the SDS-polyacrylamide gel and blocked in $30 \mathrm{~g} / 1$ gelatin for $1 \mathrm{~h}$ in tris-buffered saline at $\mathrm{pH} 7.5(20 \mathrm{mmol} / 1$ tris and $0.5 \mathrm{~mol} / 1$ sodium chloride). Then the sheets were incubated for $90 \mathrm{~min}$ in a first antibody solution at a concentration of $1: 500$. Antibodies were raised in rabbits (Dakopatts, Accurate Chemical \& Scientific Corporation, Westbury, NY, USA). After washing the nitrocellulose sheets in tris-buffered saline (four times for $20 \mathrm{~min}$ at room temperature), they were incubated with a second anti-rabbit antibody coupled with horseradish peroxidase (Bio-Rad Laboratories, Richmond, CA, USA) at a concentration of $1: 1500$. Again the sheets were washed extensively in tris-buffered saline, and specific proteins were visualized by addition of 4-chloro-naphthol and hydrogen peroxide.

\section{Results}

The most obvious differences between 2-DE gels of proteins from serum and CSF are apparent in figure 1 . The protein pattern of both specimens are comparable when CSF is concentrated approximately 100 to 200 fold. The spots visible within area 8 (fig. 1) are present in most CSF specimens but are absent from serum. This area includes apolipoprotein $\mathrm{E}$ and several other sets of spots with different charges and molecular mass. No clear relation could be found between these spots and any diseases, but the proteins in this area seem to be more prominent in inflammatory states. The light chains in CSF differ from those in serum as exemplified by spots $12-17$ in figure 1 . The difference in spot 15 is characteristic for 2-DE gels of CSF and is not apparent in other biological fluids (amniotic fluid, urine, saliva, pleural and abdominal effusions) that we have studied.

The relative amount of transthyretin (area 11 in fig. 1) is increased in CSF compared with serum. The cathodic end of transferrin (area 4 in fig. 1) is more basic in CSF than in serum. Also, the heavy chains of IgG (gamma chains in fig. 1) in CSF differ from those in serum with the basic end of the chain being less pronounced. The electrical charges of the gamma heavy chain subunits are somewhat different.

\section{Changes associated with pathological states}

Patients in whom we suspected disturbance of the blood-brain or blood-CSF barrier demonstrated a relative incrèase in serum-derived proteins in their CSF compared with the CSF from healthy individuals. Such proteins are usually present in small amounts in the CSF of normal individuals. Some proteins, such as the beta chain of haptoglobulin and $\alpha_{1}$-antichymotrypsin, are less concentrated in CSF than in serum. The patterns of subunits of the light chains are different in CSF and serum (fig. 2).

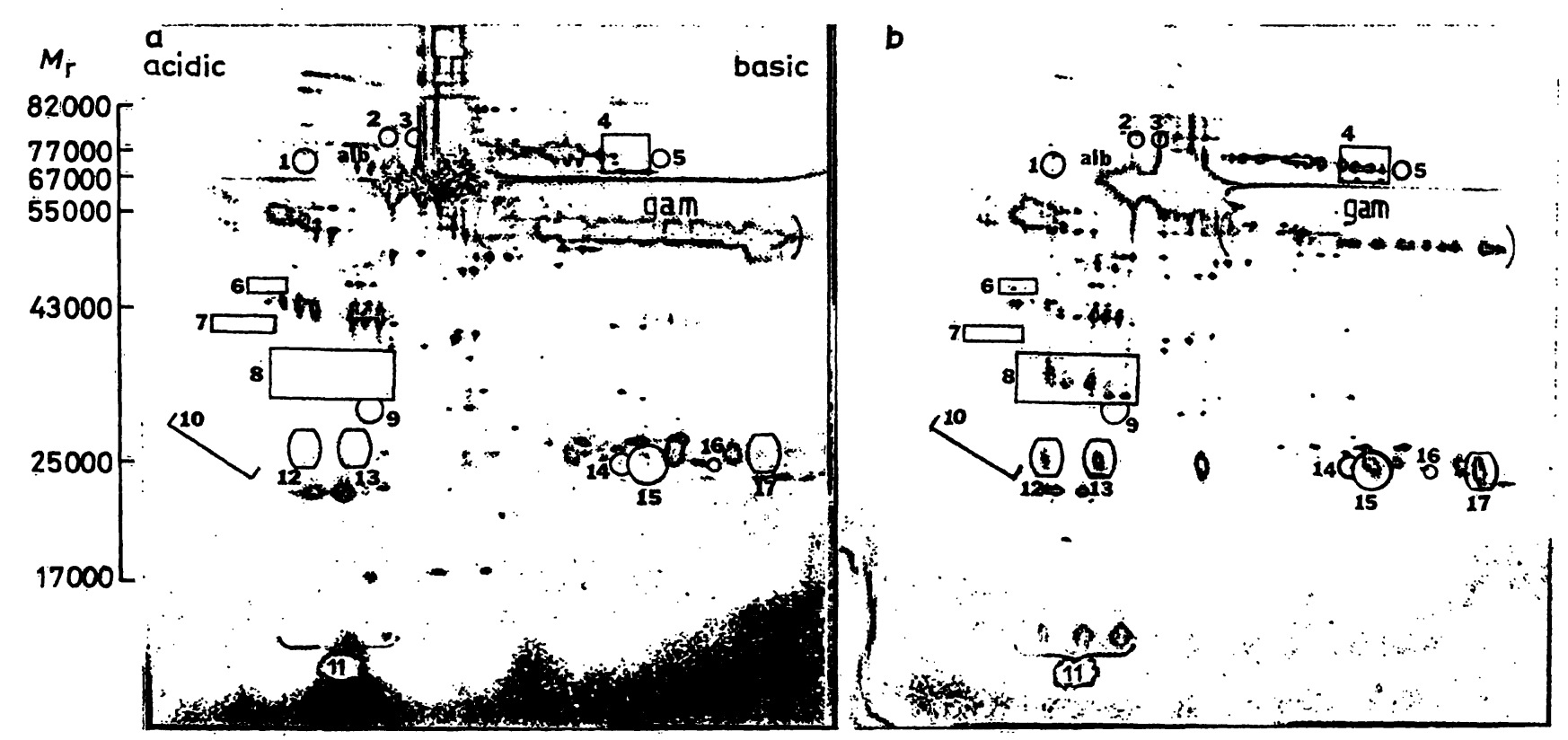

Fig. 1. Comparison of 2-DE gels of (A) serum from a healthy control person, (B) CSF from a patient with atypical facial pain. Spots characteristic of CSF proteins are marked 1-17. $4=$ basic end of transferrin, 11 = transthyretin, $12-17=$ spots within light chain area, (alb = albumin, gam $=$ heavy chains of $\mathrm{IgG})$. 


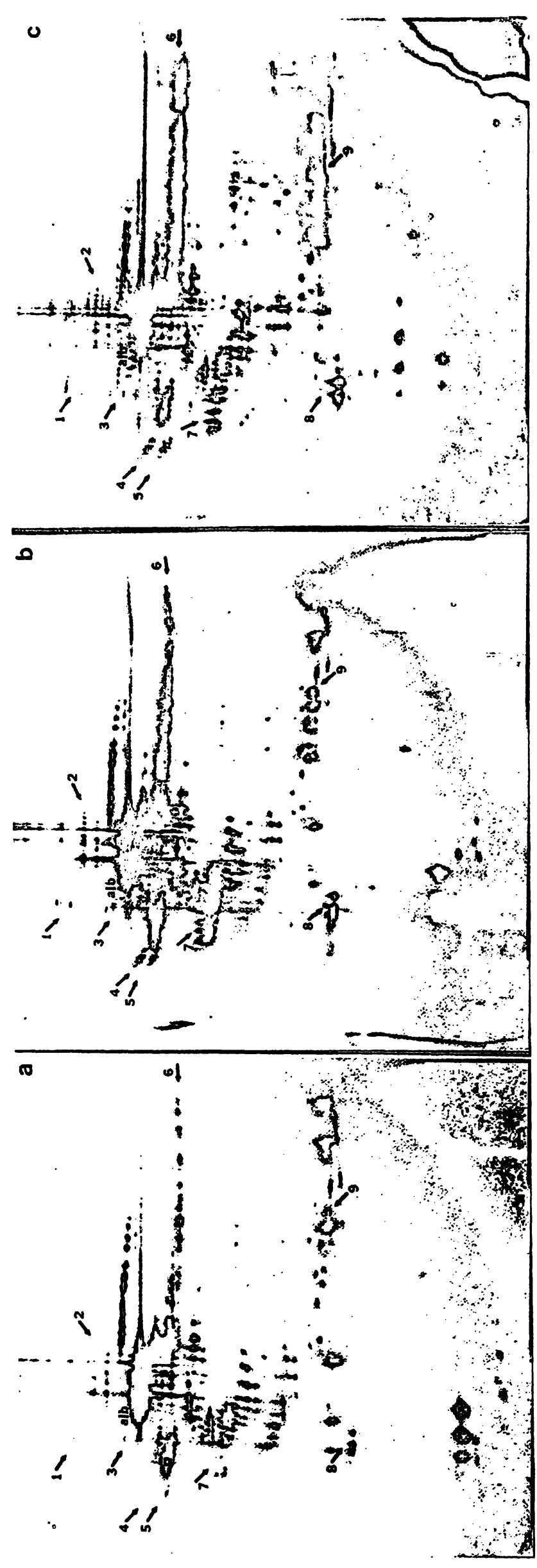

Some patients with malignant diseases and neurological symptoms, suggesting involvement of the CNS, demonstrated several characteristic protein spots on their 2-DE gels (fig. 3). Many of these are present in the area at the acidic end of the light chains, particularly in patients with leukaemia involving the CNS. A series of three to four spots of relative molecular wight of approximately 60000 and an isoelectric point of approximately $\mathrm{pH} 7.0$ have been observed on 2-DE gels of CSF from 3 patients with leukaemia without involvement of CNS. None of the patients had been treated with intrathecal cytostatic agents.

Patients with multiple sclerosis showed characteristic protein patterns in the light chains with some augmentation of other spots normally present in this region. These included distinctive, sharply edged spots (fig. 4). We selected ten different locations within this area on 2-DE gels of CSF from patients with different degrees of severity of multiple sclerosis for the evaluation of the relationship of the spots to the disease as indicated in figure 4. Some of these spots are present in 2-DE gels from patients with other diseases, but to a lesser extent. In table 2 the distribution and frequency of these spots are listed. All spots which are classified as $\alpha$ have clearly defined edges and are distinct. $\beta$ indicates that an area contains a protein spot with a less defined edge (diffuse spots). - indicates that no protein is visible within a spot area. Spots within areas $6,7,8,9$, and 10 (fig. 4) typically have well defined edges. For spots in these areas the signs ++ , and + , refer to the amount of protein. The combined frequency of $\alpha$ and ++ spots from CSF of patients with multiple sclerosis and other demyelinating diseases was significantly different $(p<0.01)$ from CSF from patients without clinical evidence of demyelinating diseases. We also calculated the specificity and sensitivity of each spot for multiple sclerosis (18). One value was calculated for sensitivity and specificity for spot areas classified with both $\alpha$ and ++ and another value for spots classified with both $\alpha$ and ++ together with $\beta$ and + . The true positive rates (sensitivity) were plotted against the false positive rates $(1$ - specificity), and receiver operating characteristic (ROC) curves were drawn (fig. 5). The detection of a protein within spot areas with + and ++ and $\alpha$ and $\beta$ reveals a high

Fig. 2. 2-DE gels of (a) CSF of a normal patient, (b) CSF of a patient with a disc syndrome and (c) serum of a normal control person. Serum-specific spots in CSF which indicate a damaged blood-brain or blood-CSF barrier are marked with arrows and are numbered 1-9 (alb = albumin). Note these numbers do not correspond to the same numbered spọts in figure 1 . 


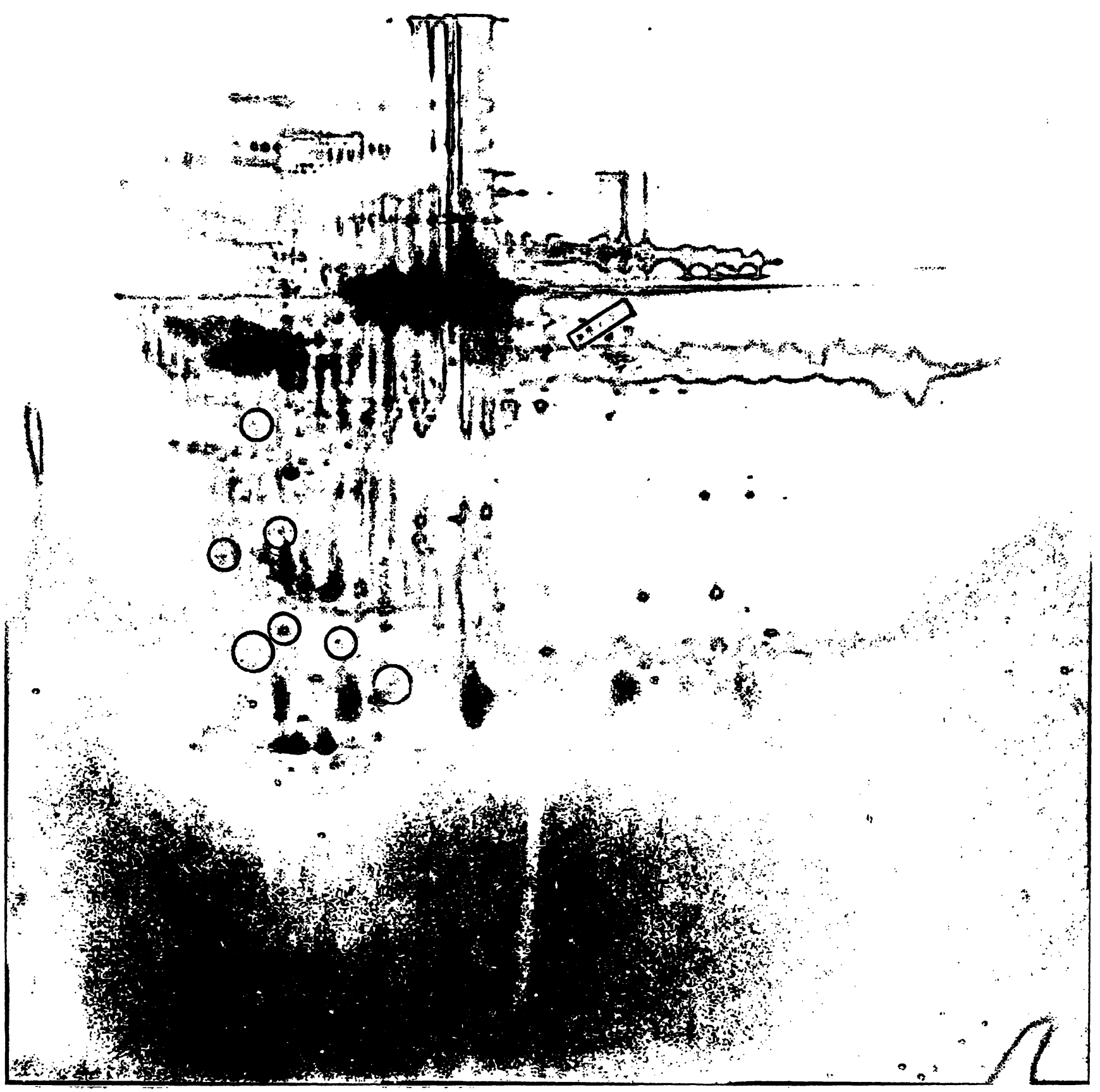

Fig. 3. 2-DE of CSF from a patient with acute lymphatic leukaemia. Spots within the rectangle were found in three other patients with the same disease. The other marked spots were only found in this specimen.

sensitivity, but low specificity for the diagnosis of multiple sclerosis. On the other hand, the evaluation of sharp edged spot formation in spot areas 1-5 (classified with $\alpha$ ) and high concentrations in spot areas 6-10 (classified with ++ ) against spots with blurred boundary (classified with $\beta$ ) or low concentrations (classified with + ) or absence (classified with -) improves specificity but diminishes sensitivity. Spots $6-10$ showed a positive correlation with sensitivity and a negative correlation with specificity with respect to the quantity of protein. Spots within the areas 1-5 demonstrated good specificity for multiple sclerosis, if their edges are well defined. If these spots are evaluated depending on their presence only (spots with well $[\alpha]$ or ill $[\beta]$ defined edges) sensitivity increases, but specificity diminishes. Spots within areas $1-4$, and 10 show a high specificity but a relatively low sensitivity for multiple sclerosis. No obvious differences in the light chain region could be found between patients with the different subclasses.

2-DE of CSF from two patients with multiple sclerosis and from one patient without any obvious neurological or systemic disease, as well as one human serum, were blotted on nitrocellulose sheets and stained with peroxidase-labeled antibodies against the immunoglobulin light chains kappa and lambda. The nature of the multiple sclerosis-associ- 


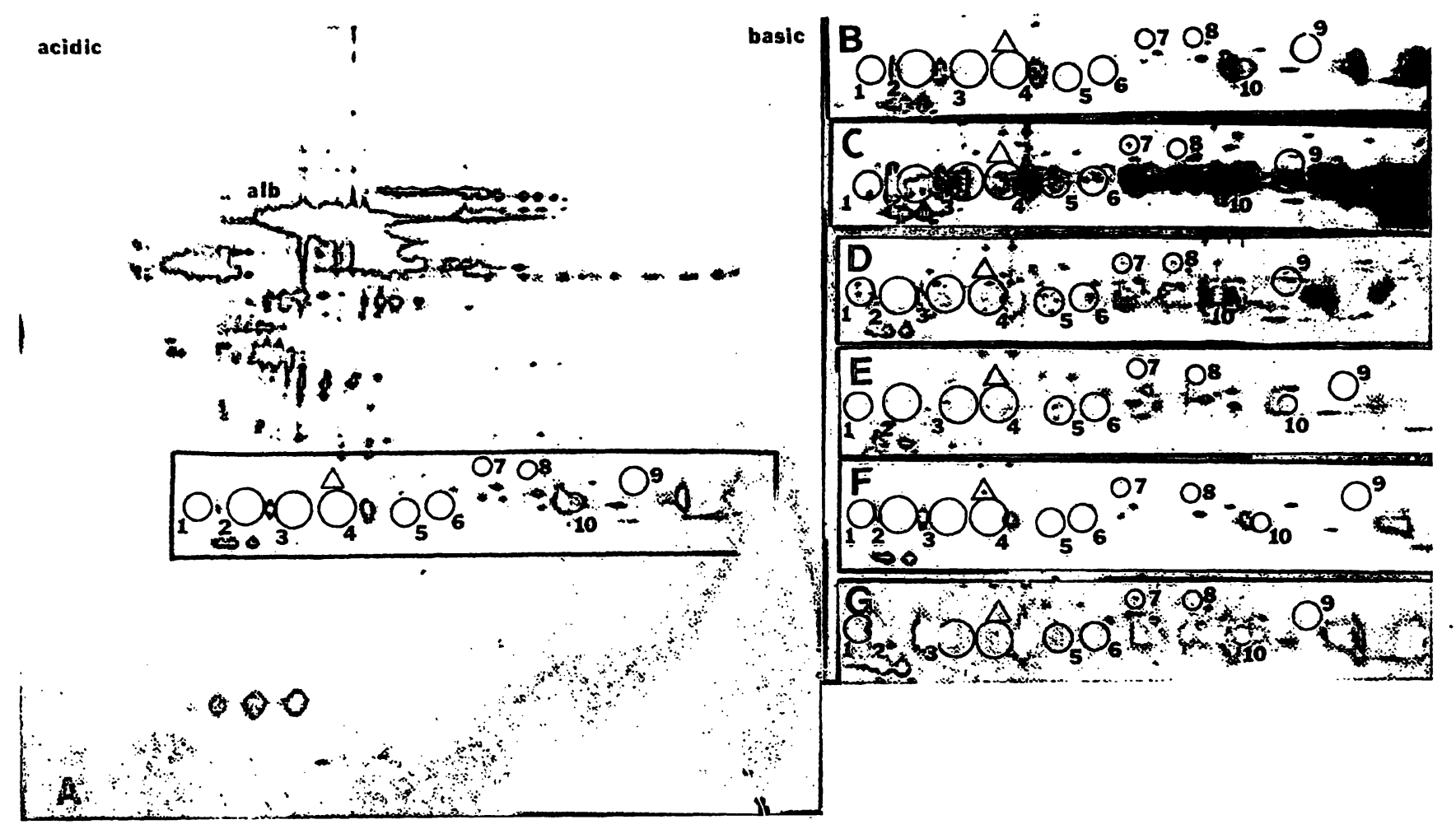

Fig. 4. A) 2-DE gel of CSF of a normal control person. The light chain area is marked. Spot areas $1-10$ marked with circles are associated with multiple sclerosis. B) light chain area of 2-DE gel of CSF of a normal control person. C) and D) light chain areas of 2-DE gels of CSF of patients with multiple sclerosis. E) light chain area of a 2-DE gel of a patient with encephalomeningitis. F) light chain area of a 2-DE gel of CSF of a patient with Parkinson's disease. A diseaseassociated spot is within the triangle. G) light chain area of a 2-DE gel of a patient with Alzheimer's disease. The spot apparently associated with Parkinson's disease can be recognized in the triangle. The numbering of these spots is not the same as in figures 1 and 2.

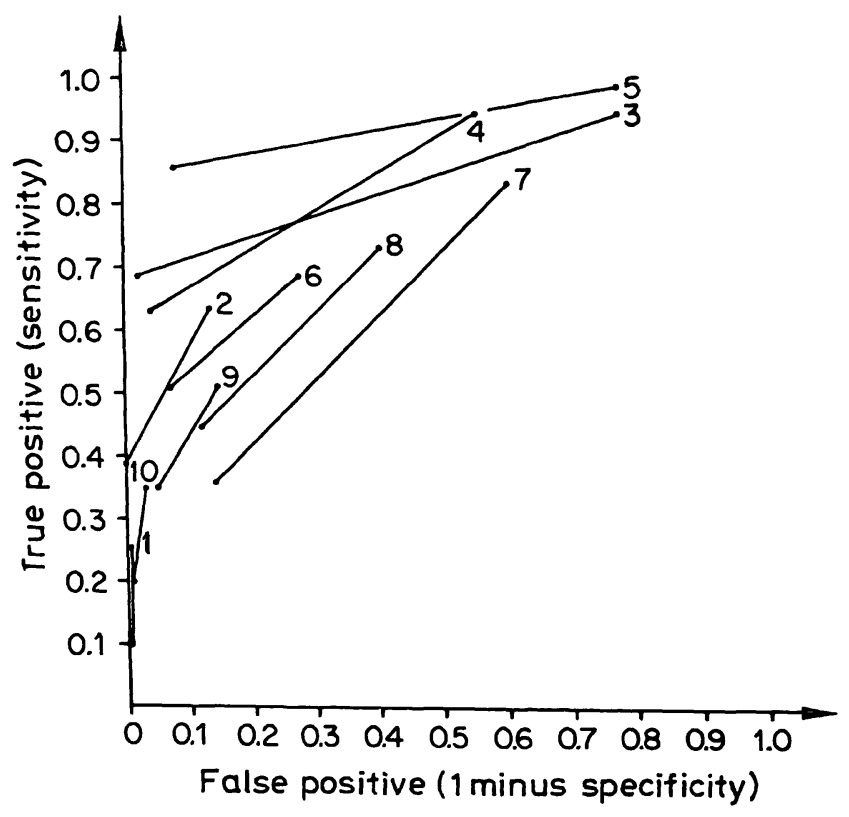

Fig. 5. ROC curves of the 10 spots associated with multiple sclerosis. Numbers are taken from spot areas as described in figure 4 and table 2 . Specificity and sensitivity relate to the diagnosis of multiple sclerosis. The increase of specificity and decrease of sensitivity can be recognized if the spot areas are classified only with ++ and $\alpha$. If only the presence of a protein within the spot areas (classified as + and ++ as well as $\alpha$ and $\beta$ ) is used for classification there is a high sensitivity, but low specificity. ated spots could not clearly be determined by this method. Therefore we took CSF specimens from other patients with the same diagnosis, and depleted the immunoglobulin light chains (kappa and lambda) by immunoabsorption. One CSF specimen of a patient with multiple sclerosis was absorbed twice before analysis by 2-DE. Spots 2, 3, and 4 in figure 4 largely disappeared with absorption, although they were still faintly visible, while the spots $1,5,6,7,8$, 9 , and 10 of figure 4 disappeared completely. Nevertheless, the strong reaction suggests that the multiple sclerosis-associated proteins in the light chain region are immunoglobulin light chains themselves or proteins which show a very high cross-reactivity with immunoglobulin light chains.

Laboratory data concerning the CSF IgG index (ratio of IgG and albumin in CSF divided by the ratio of IgG and albumin in serum) and the presence of oligoclonal bands (determined by agarose gel electrophoresis) were available in only a few càses. Whenever the CSF IgG index was increased or oligoclonal bands were present, the spots associated with multiple sclerosis were observed on 2-DE gels of CSF within the light chain area. There was no; single spot area 


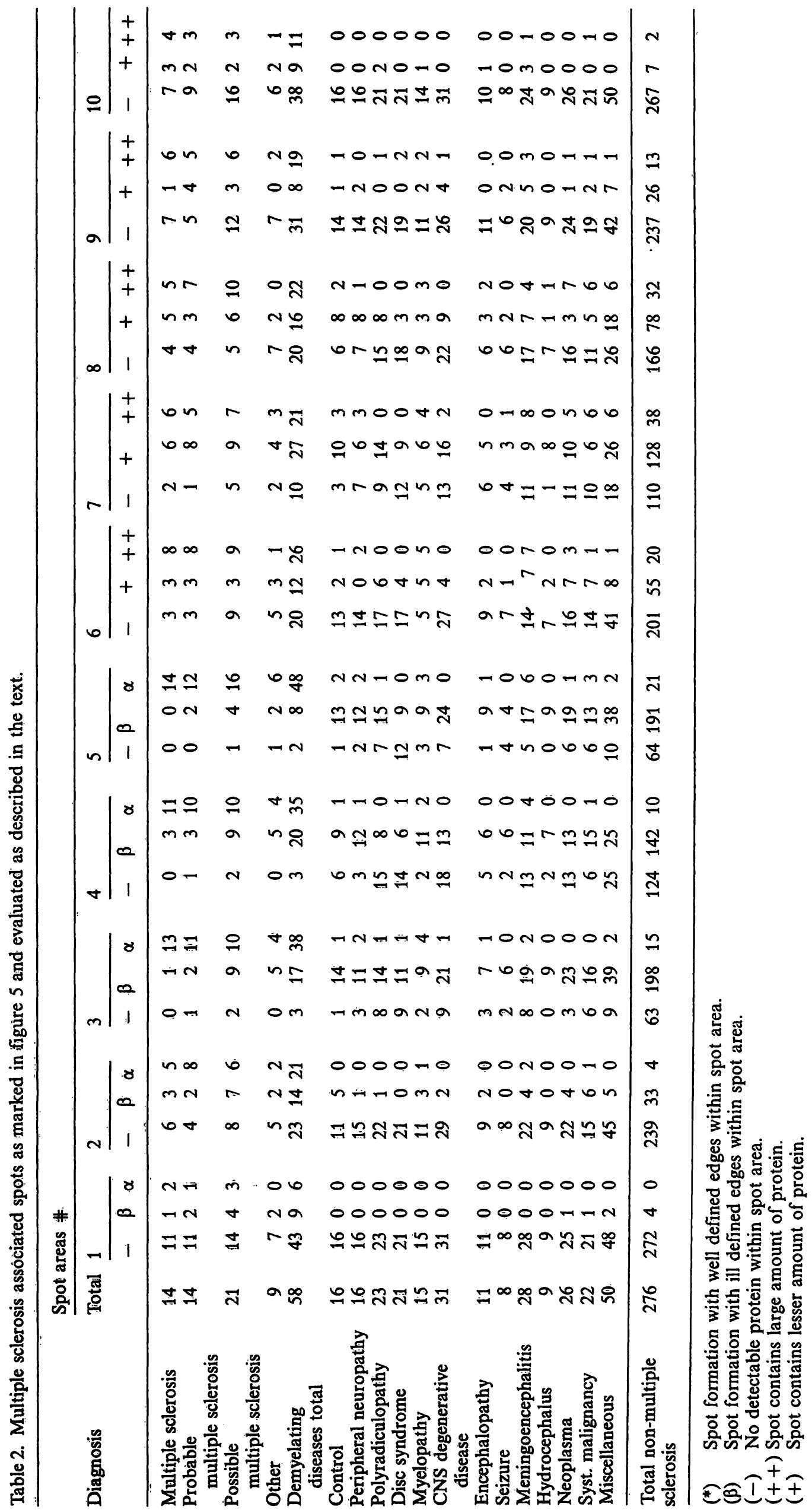


that was characteristic of a high index or presence of oligoclonal bands, and several patients demonstrated multiple sclerosis-associated spots, although their CSF IgG index was in the reference range and no oligoclonal bands were present.

A protein spot described as specific for Parkinson's disease by Harrington \& Merril (7) was also found in all three patients with this disease whom we investigated (fig. $4 \mathrm{~F}$ ). However, the same spot was also in the CSF of about one half of the patients with Alzheimer's disease and other dementias and, to a much lesser extent, in CSF specimens from patients with other diseases (fig. $4 \mathrm{E}$ ).

\section{Discussion}

As our normal control population, we selected CSFs from patients who showed no evidence of any neurological or systemic disease, and established a reference map for 2-DE gels of CSF which has been published previously (2). This map shows several additional proteins not present in the map of CSF from normal individuals published by Goldman et al. (5). However, it is uncertain whether these differences are related to the use of different silver stains or to different control populations.

The protein concentration of CSF is about one twohundredth of that in serum. We always loaded ISOgels with the same amount of protein to facilitate interpretation of gel patterns. The protein concentrations in the CSF specimens varied from $18 \mathrm{mg} / \mathrm{l}$ to more than $100 \mathrm{mg} / \mathrm{l}$. Therefore different volumes of CSF were subjected to 2-DE. Upon comparing 2$\mathrm{DE}$ gels from serum and from concentrated CSF containing the same amount of protein, we identified several spots which are present in CSF only. This does not mean that they are not derived from serum, because they could be present at a concentration below the threshold of detection.

Comparison of 2-DE gels of serum and CSF shows that proteins in spot area 8 (fig. 1) are present in concentrated CSF but not in serum, but no relationship could be established with any disease state. We suspect that this group of spots is associated with inflammatory states affecting the CNS. Spots of area 8 (fig. 1) are similar in appearance to apolipoproteins on 2-DE gels stained with silver nitrate with the method described by Oakly (16) and the area overlaps apolipoprotein E in 2-DE gels of serum (15). This area consists of at least three different proteins (19).

Spots of area 10 in figure 1 have been described as specific for CSF (6). However, we have observed these spots in 2-DE gels of pleural and abdominal effusions and in sera which have been stored over several years in a freezer with multiple freeze-thawings (personal observation). The spots may therefore be related to degradation of larger proteins. Their presence in CSF may indicate either enhanced degradation of proteins in CSF or slow metabolic elimination of degraded proteins from the CSF. Additionally these spots reacted with antibodies against light chains which suggests an antigenic relationship with these immunoglobulin subunits.

Transthyretin (spot 11 in fig. 1), which appears to contain more acidic subunits in CSF than in serum (6), is present normally at a higher concentration in CSF than in serum. When the serum transthyretin is increased, additional acidic subunits show up on 2DE gels (15).

Anderson \& Anderson have demonstrated micro= heterogeneity of transferrin in serum due tó neuraminidase digestible residues (21). The anodic end of transferrin, which is much more pronounced in CSF than in serum, may be due to a diminished amount of neuraminidase digestible residues since, treatment of serum with neuraminidase produced a similar transferrin pattern on their 2-DE gels. A conversion of iron-1-transferrin to apo-transferrin might also be a reason for the more basic appearance of transferrin on 2-DE gels of CSF when compared with 2-DE gels of serum.

The relative increase of some serum proteins in CSF in patients with a damaged blood-brain or bloodCSF barrier suggests that quantitative analysis of these protein spots might produce further information on the degree of damage. Thus the absolute amount of protein together with the molecular size and charge of specific proteins might be of value in assessing the extent of damage.

The spots we have found in CSF of patients with malignancies involving the CNS were not constant from patient to patient, except for a series of spots which we found in three patients with acute lymphatic leukaemia. Each of these spots must be characterized, and investigated in other patients with leukaemia and other diseases to establish its diagnostic specificity.

Certain immunoglobulins have been described as oligoclonal bands in CSF of patients with multiple sclerosis. They also appear in other inflammatory processes of the CNS which are usually accompanied by increased immunoglobulin concentrations in the CSF. Oligoclonal bands in CSF are not specific for multiple sclerosis (1). Changes in the light chain area and particularly the formation of additional spots have been noted with 2-DE previously $(2,3,8,21)$. The density of these areas correlated well with oligoclonal band formation $(3,8)$. 
In this study we decided to characterize spots which seemed to be associated with multiple sclerosis according to their sharp edge and clearly distinguishable nature (fig. 4, tab. 2). Immunoabsorption and immunoblotting demonstrated that these spots were apparently light chains. In one patient with multiple sclerosis, spot areas 2, 3, and 4 could not be completely eliminated in the specimen, even after double absorption before analysis by 2-DE. The reason is not clear. We postulate that these spots are formed by immunoglobulin light chains themselves or proteins which have a high cross-reactivity with immunoglobulins. Walsh et al. also describe certain spot formation in the light chain area of 2-DE gels of CSF of patients with multiple sclerosis. They present strong evidence that they are clonal formations of light chains (9).

The diagnostic relevance of the light chain area on 2-DE gels from CSF of patients with multiple sclerosis is of interest. Harrington et al. (8) described certain areas as multiple sclerosis-related, and these appear to be the same as our multiple sclerosisassociated areas. Their spot area \#118 seems to be identical to our spot area \#2 (fig. 4), their spot area \#119 with our spot area \#3, their spot area \#115 with our spot area \#4, and their spot area \#114 with our spot area \#5. The more basic light chain spots in our gels are outside the range of these investigators' isoelectric protein separation. By adding basic amino acids and a highly concentrated catholyte we achieved better resolution on the basic side of the gel (15). Additionally, differences in the technique, reagents and patient selection may give rise to the differences between their pattern and ours. It is possible that additional spots might be found in the basic end of the light chain region using a different isoelectric gradient for the first dimension. Harrington et al. (8) describe an increased density in different areas, while we found spot formations not only in these areas but also in other areas. Multiple sclerosis is a diagnosis which is mainly established by clinical characteristics. Biochemical parameters such as CSF IgG concentration, CSF IgG index, or oligoclonal banding do not necessarily concur with the clinical diagnosis of multiple sclerosis (1). Some patients in the myelopathy group probably have multiple

\section{References}

1. Cutler, R. W. P \& Spertell, R. P. (1982) Ann. Neurol. 11, 1-10 (review).

2. Endler, A. T., Young, D. S., Currie, R. M. \& Yanagihara, T. (1984) Two-dimensional electrophoresis of human cerebrospinal fluid. In: Electrophoresis '84, (Neuhoff, V., ed.) Verlag Chemie, Weinheim, FRG. pp. 273-275. sclerosis. The spots were found in the same area in 2-DE gels of CSF of patients with meningoencephalitis, but were not usually in a configuration typical for multiple sclerosis (fig. 4). We classified them as ++ , because differentiation is difficult.

The variability of the light chain patterns in 2-DE gels of patients with multiple sclerosis might indicate biochemical and immunological variations connected with this disease. The presence of these spots suggests that patients with multiple sclerosis may form some type of atypical immunoglobulins. Many theories exist about the pathogenesis of multiple sclerosis, including direct and indirect virus effects, autoimmune processes, and deficiencies of the immunoregulatory system (22). The association of the formation of all or some of these multiple sclerosis-associated spots with a pathogenic agent such as a virus or autoantigen, or with disturbance of the immunoregulatory system remains to be investigated. The statistical evaluation and the ROC curves show that some of these spots have a high specificity for multiple sclerosis, but a low sensitivity. The evaluation of the presence of protein in the spot areas is highly sensitive for multiple sclerosis, but may not be adequate for the diagnosis of multiple sclerosis, because high specificity is also required (23).

Harrington \& Merril have described a spot on 2-DE gels of CSF that is associated with Parkinson's disease (7). We observed this spot in three patients with this disease, but also in some patients with other degenerative diseases. The diagnostic specificity of this protein has still to be investigated.

High resolution 2-DE is a potential tool for investigation of the protein pattern of CSF. Using various neurological disorders, we have demonstrated the potential of this technique for detecting disease-specific changes in the protein pattern in CSF.

\section{Acknowledgement}

This study was made possible by the Max Kade Foundation which supported the leave of Dr. A. Thomas Endler from the University of Vienna, Austria. The project was started at the Mayo Clinic and finished at the University of Pennsylvania. We also acknowledge support by Electro-Nucleonics, Inc.
3. Wiederkehr, F., Ogilvie, A. \& Vonderschmitt, D. J. (1985) Clin. Chem. 31, 1537-1542.

4. Dermer, G. B., Silverman, L. M. \& Chapman, J. F. (1982) Clin. Chem. 28, 759-765.

5. Goldman, D., Merril, C. R. \& Ebert, M. H. (1980) Clin. Chem. 26, 1317-1322. 
6. Walsh, M. J., Limos, L. \& Tourtellotte, W. W. (1984) J. Neurochem. 43, 1277-1285.

7. Harrington, M. G. \& Merril, C. R. (1984) Clin. Chem. 30, 1933.

8. Harrington, M. G., Merril, C. R., Goldman, G., Xu, X. H. \& McFarlin, D. E. (1984) Electrophoresis 5, 236-245.

9. Walsh, M. J., Wallace, W. T., Roman, J. \& Dreyer, W. (1985) Clin. Immunol. Immunopathol. 35 313-327.

10. Thompson, E. J. (1982) Brit. J. Hosp. Med. 28, 600-608 (review).

11. O'Farrell, P. H. (1975) J. Biol. Chem. 250, 4007-4021.

12. Anderson, N. L. \& Anderson, N. G. (1977) Proc. Natl. Acad. Sci. USA, 74, 5421-5425.

13. Switzer, R. C., Merril, C. R. \& Shifrin, S. A. (1979) Anal. Biochem. 98, 231-237.

14. Merril, C. R., Switzer, R. C. \& van Keuren, M. (1979) Proc. Natl. Acad. Sci. USA 76, 4335-4338.

15. Tracy, R. P. \& Young, D. S. (1984) Clinical applications of two-dimensional gel electrophoresis. In: Two-dimensional gel electrophoresis of proteins (Celis, J. E. \& Bravo, R., eds.) Academic Press Inc., Orlando, FL, pp. 193-240.
16. Oạkley, B. R., Kirsch, D. R. \& Morris, N. R. (1980) Anal. Biochem. 105, 361-363.

17. Symington, J. (1984) Electrophoretic transfer of proteins from two-dimensional gels to sheets and their detection. In: Two-dimensional gel electrophoresis of proteins (Celis, J. E. \& Bravo, R., eds.) Academic Press, Inc., Orlando, FL, pp. 127-168.

18. Cembrowski, G. S. \& Sullivan, A. M. (1985) Quality control and statistics. In: Clinical chemistry, principles, procedures, correlations (Bishop, M. L., Duben-von Laufen, J. L. \& Fody, E. P., eds.) J. B. Lippincott Co., Philadelphia, PA, pp. 57-86.

19. Dermer, G. B. \& Edwards, J. J. (1983) Electrophorèsis 4, 212-218.

20. Anderson, M. L. \& Anderson, N. G. (1979) Biochem. Biophys. Res. Commun. 88, 258-265.

21. Jellum, E. \& Thorsrud, A. K. (1982) Clin. Chem. 28, $876-883$.

22. Ford, H. C. (1985) Clin. Biochem. 18, 3-13 (review).

23. Galen, R. S. (1979) Diagn. Med. 2, 23-31.

Dr. A. Thomas Endler Institut für Klinische Chemie und Laboratoriumsdiagnostik Lazarettgasse 14 A-1090 Wien 